\title{
A construção simbólica da definição de governar e de gover- nador realizada pelo jornal Zero Hora nas três últimas eleições gaúchas
}

\author{
Maria Ceci Misoczky* \\ Carolina da Silva Ferreira**
}

\section{Resumo}

Este artigo é um dos produtos de uma pesquisa que considera as ações discursivas como fundamentais para a constituição e sustentação de relações de poder, para a capacidade dos diferentes atores sociais manejarem processos discursivos e para a luta para privilegiar tipos particulares de discurso em detrimento de outros. 0 tema central é compreender a contribuição do jornal Zero Hora para a configuração do campo da administração pública no estado do Rio Grande do Sul, focalizando, em particular, a construção simbólica do significado de governar e de governador. Após uma apresentação do campo dos estudos do discurso e dos principais referenciais aqui adotados, além de uma breve apresentação de alguns estudos que também tomaram o Zero Hora como objeto, são explicitados os procedimentos metodológicos adotados. A análise crítica do discurso do Zero Hora na cobertura das três últimas eleições para 0 governo do estado do Rio Grande do Sul indica uma ênfase no governar como um ato de conciliação e na figura do governador como uma administrador modernizante.

Palavras chave: Análise de discurso. Governar. Construção simbólica

\begin{abstract}
This article the result of a research that considers discoursive actions as foundations for the constitution and maintenance of power relations, for the ability of different social actors to deal with discoursive processess and for the struggle around the privilege of specific types of disourse over others. The central issue is to understand the contributions of the newspaper Zero Hora to the configuration of the public administration field in the state of Rio Grande do Sul. The focus is the simbolic construction of the meaning of 'to govern' and 'governor'. After a presentation of the discourse studies field, of the main references adopted and a brief presentation of studies of Zero Hora, we present the methodologica procedures. The cricital analysis of discourse produced by Zero Hora during the coverage of the three last elections for the govern of Rio Grande do Sul, indicates the conception of to govern as an act of conciliation, and the image of governor as a modernizer manager.
\end{abstract}

Key words: Discourse analysis. To govern. Simbolic construction

\section{Introdução}

Este artigo é um dos produtos de uma pesquisa ${ }^{2}$ que considera as ações discursivas como fundamentais para a constituição e sustentação de relações de poder, para a capacidade dos diferentes atores sociais manejarem processos discursivos e para a luta para privilegiar tipos particulares de discurso em detrimento de outros (FAIRCLOUGH e WODAK, 1988). A partir dessas referências, surge o interesse em abordar aspectos da administração pública - as definições de governador e de governar -, de um modo que incorpore a complexidade das interações entre esse campo de conhecimento e práticas e os campos do jornalismo e da política.

\footnotetext{
${ }^{1}$ Financiada pela Fapergs.
}

Docente e pesquisadora do Programa de Pós- Graduação em Administração -Escola de Administração da UFRGS. E- mail: mcaraujo@ ea.ufrgs.br. Endereço: Escola de Administração/UFRGS - Washington Luis, 855 - Porto Alegre - RS - CEP 90010-460.

** Mestranda em Administração no Programa de Pós Graduação em Administração -Escola de Administração da UFRGS.E-mail: carolbio@ terra.com.br. Endereço: Escola de Administração/UFRGS - Washington Luis, 855 - Porto Alegre - RS - CEP 90010-460. 
Para tanto, se parte da concepção de campos de poder, formulada por Pierre Bourdieu (1996), como campos de forças e de lutas em que os atores sociais com interesse no que ali se disputa - a partir das posições que ocupam e dos recursos de poder que controlam - se mobilizam para ter o monopólio sobre os tipos de capital (recursos de poder) efetivos, bem como para constituir modos legítimos de reprodução das bases de dominação.

Um recurso de poder especialmente relevante para a construção de modos legítimos de dominação é o poder simbólico, entendido como poder de constituir o que existe pela enunciação, "de fazer ver e de fazer crer, de confirmar ou de transformar a visão de mundo e, por isso, a ação sobre o mundo e, portanto, o mundo". (BOURDIEU, 1977, p.410). Ou seja, um recurso crítico na luta por impor representações hegemônicas do mundo social.

Este artigo aborda a definição de conceitos produzida por uma organização que se localiza no campo do jornalismo - o jornal Zero Hora. No entanto, é preciso ter claro que a identificação das fronteiras entre o campo do jornalismo e o campo da política é praticamente impossível, já que o campo do jornalismo produz e impõe uma visão inteiramente particular do campo da política. Os meios de comunicação de massa são mediadores entre os diferentes campos sociais - "mediador não é o mesmo que intermediário, pois na mediação há produção de sentidos." (BERGER, 2002, p.1).

Para Jovchelovitch (2000, p.91), a tendência dos meios de comunicação de massa para produzir significados e valores hegemônicos não deve ser subestimada, especialmente, onde "a ausência de uma esfera pública impede o escrutínio dos interesses privados que dirigem a indústria de comunicação". Essa autora levanta, expressamente, a questão sobre em que medida "a mídia impõe definições sobre a vida pública quando apóia abertamente algumas políticas e seus defensores e exclui outros".

O objetivo deste estudo não é compreender as lutas que se travam no campo do jornalismo; não é analisar a imprensa como um fenômeno em si mesmo; não é, também, estudar a relação entre o campo da política e o campo midiático, ainda que se concorde com Berger (2002, p.1) e sua afirmação de que esse é um dos aspectos mais intrigantes da atualidade. O tema central é compreender a contribuição do jornal Zero Hora para a configuração do campo da administração pública no estado do Rio Grande do Sul, focalizando, em particular, a construção simbólica do significado de governar e de governador. Embora o conteúdo se refira a um caso regionalmente localizado, a contribuição deste artigo excede os aspectos localizados se considerarmos a universalidade do fenômeno da influência da mídia em todas as esferas da vida social. Além disso, as discussões em torno do desenvolvimento metodológico aqui apresentado podem vir a contribuir para a ampliação do estudo dessa temática.

O texto que segue está organizado da seguinte forma: uma apresentação do campo dos estudos do discurso e dos principais referenciais aqui adotados, uma breve apresentação de alguns estudos que também tomaram a Zero Hora como objeto, os procedimentos metodológicos adotados, a análise crítica do discurso da Zero Hora e suas implicações para a construção simbólica das definições de governar e governador na cobertura das três últimas eleições para o Governo do Estado do Rio Grande do Sul. Seguem-se as considerações finais.

\section{Estudos críticos do discurso}

A pesquisa que realizamos se insere na visão de que a linguagem - ou, mais amplamente, a semiose - é uma parte irredutível do processo social. Assume-se que a vida social é uma rede interconectada de práticas de produção de diversos tipos - econômica, política, cultural etc. Cada prática de produção da vida social é, parcialmente, uma prática semiótica. A análise crítica da semiose, por sua vez, é a análise dialética do relacionamento entre discurso e outros elementos do processo social, considerando a linguagem como ação e como representação (FAIRCLOUGH, 2002). 
Dentro da vertente da análise da semiose adota-se o foco nos efeitos dos textos sobre a construção da sociedade e, mais especificamente, na análise crítica de discurso (ACD), definida por Fairclough e Wodak (1998) como uma abordagem de situações de interação social que tomam uma forma lingüística.

Descrever o discurso como uma prática social implica uma relação dialética entre um evento discursivo particular e o contexto, instituição ou estrutura social em que ocorre; reconhecendo que o evento discursivo é moldado por esses, mas que também os molda. Ou seja, o discurso é socialmente constituído assim como é constitutivo: ele constitui contextos, objetos de conhecimento, assim como identidades sociais e relacionamentos entre pessoas e grupos de pessoas. Além disso, o discurso ajuda a produzir e a reproduzir coisas e posições através do modo como as representa e as posiciona - diferentes conceitos produzem diferentes objetos. O método da ACD inclui a descrição da linguagem do texto - utilizando categorias como as que se encontram no quadro 1 -, a interpretação das relações entre o processo discursivo e o contexto, e explicitação das relações entre o processo discursivo e o processo social.

Adotando a ACD, Hardy e Phillips (1999) focalizam como a ação discursiva estrutura um campo através da constituição de conceitos, objetos e posições do sujeito.

- o discurso produz um conjunto de conceitos - idéias, categorias, relações e teorias através dos quais compreendemos o mundo e nos relacionamos uns com os outros - que são mais ou menos contestados e que são cultural e historicamente situados. Conceitos são considerados como objetos de conhecimento e como significados intersubjetivos. Dependem da contínua construção de textos para significar algo, e podem, portanto, mudar ao longo do tempo e de um contexto para outro, na medida em que textos são produzidos, disseminados e interpretados;

- alguns conceitos existem somente na ordem expressiva, enquanto outros podem ser vinculados a um material referente para produzir um objeto. Desse modo, discursos tornam o mundo material significativo. Ou seja, alguns conceitos estão discursivamente ligados a partes particulares de um mundo material ambíguo - um mundo que tem um status ontológico e uma existência física, independente da nossa experiência com ele -, e o papel do discurso na constituição dos objetos freqüentemente inclui utilizar diferentes conceitos para produzir diferentes objetos;

- a posição do sujeito também é construída no discurso. Falar dentro de um discurso requer que o ator escolha uma dentre um número limitado de posições. Em outras palavras, afirmações dentro de um discurso não são produzidas independentemente do sujeito atuante, mas, em vez disso, ajudam a posicionar e a produzir o sujeito no contexto de um discurso particular. 


\section{Quadro 1 - Categorias para descrever o texto na análise crítica de discurso}

\begin{tabular}{|c|c|}
\hline Antítese & $\begin{array}{l}\text { Estabelece contrastes e cria diferenças - freqüentemente marcados por um movimento do } \\
\text { positivo para o negativo, ou vice-versa (" } x \text { não } y ")- \text {, "envolve todas as pessoas, e não apenas } \\
\text { algumas", "não se refere à cidadania, mas à pobreza", por exemplo }\end{array}$ \\
\hline Equivalência & Reduz diferenças, utilizando listas ou substituições, como se fossem sinônimos \\
\hline Colocação & $\begin{array}{l}\text { Coocorrências entre palavras em um texto. Podem ser identificadas pela freqüência com que } \\
\text { um adjetivo é utilizado para modificar um substantivo ("novo universalismo", por exemplo) } \\
\text { ou pela relação usual entre uma condição e o verbo que expressa a ação sobre a mesma } \\
\text { ("combater ou prevenir ou aliviar a pobreza", por exemplo) }\end{array}$ \\
\hline Metáfora & $\begin{array}{l}\text { A escolha da metáfora pode ser socialmente significativa - "o mercado está nervoso" é um } \\
\text { exemplo conhecido de todos, que confere propriedades humanas a uma reificação }\end{array}$ \\
\hline Modalidade & $\begin{array}{l}\text { Expressa nível de compromisso e pode ser de dois tipos - pretensão de verdade ("não existe } \\
\text { futuro fora da globalização", por exemplo) ou obrigação ("não podem ocorrer relações } \\
\text { comerciais fora dos tratados de comércio", por exemplo) }\end{array}$ \\
\hline Tom & Declarativo, interrogativo ou imperativo \\
\hline Nominalização & $\begin{array}{l}\text { Apresenta um processo como um nome ("a mudança é inevitável", por exemplo), tornado-o } \\
\text { genérico e vago ("o que está mudando, de que modo, em que período de tempo, quem } \\
\text { promove a mudança?") }\end{array}$ \\
\hline Voz passiva & $\begin{array}{l}\text { Omite os atores, podendo fazê-lo por vários motivos: talvez seja óbvio, talvez seja um modo } \\
\text { de ofuscar a agência e a responsabilidade }\end{array}$ \\
\hline Pressuposição & $\begin{array}{l}\text { De modo implícito toma as coisas como dadas. Algumas vezes, a pressuposição é mero senso } \\
\text { comum. Em outras, no entanto, é altamente questionável ("a flexibilização das relações de } \\
\text { trabalho é uma exigência do mercado" pressupõe que o mercado coloca uma exigência e que } \\
\text { o mercado possui existência própria, por exemplo) }\end{array}$ \\
\hline
\end{tabular}

Uma das características da ACD é que os pesquisadores tornam suas posições políticas explícitas, e focam em problemas sociais relevantes para esse desafio. Nesse sentido, antes de prosseguir, é preciso explicitar a partir de que posição realizamos este estudo. Adotamos uma ética da vida, isto é, a vida humana como conteúdo da ética. A partir daí a crítica está orientada pela possibilidade de transformar estruturas e relações que constituem e reproduzem a exclusão e a opressão (DUSSEL, 2002). Adotamos, também, a posição de Guerreiro Ramos (1989), segundo a qual uma teoria das organizações baseada no modelo centrado no mercado não poderia ser considerada aplicável a todas as formas de atividade da sociedade, pois exerceria uma influência que desfiguraria a vida humana. Lembramos que, na administração pública estamos envolvidos com escolhas e ações que precisam considerar os seres humanos em sua plenitude, o modo como agimos coletivamente, bem como as definições e papéis que correspondem ao Estado, considerando as vidas em comunidade. Portanto, rejeitamos a definição da pessoa limitada às suas preferências de consumo e da ação coletiva como um processo de agregar interesses individuais, que resultará em uma definição ótima do interesse público e do Estado como mera fração do mercado.

\section{Procedimentos metodológicos}

A estratégia de pesquisa deste estudo adotou uma perspectiva construcionista (IBÁNEZ, 1994; LINCOLN e GUBA, 2000) e de acordo com a hermenêutica crítica (RICOEUR, 1989).

Foram revisadas todas as edições diárias do jornal Zero Hora, no período que vai de 60 dias antes do primeiro turno das eleições até 120 dias após a posse do governador, nos processos eleitorais de 1994, 1998 e 2002. Foram considerados como matéria para análise aquelas charges, artigos, colunas assinadas, editoriais políticos e editoriais gerais que continham referências à imagem simbólica (figura do governador) e a conteúdos da prática (ato de governar). A análise pragmática de amostras de textos utiliza as categorias expressas no quadro 1, tendo-se sempre em mente o contexto e as referências a outros textos intertextualidade. 


\section{O jornal Zero Hora (ZH)}

O ZH é o jornal de referência no Rio Grande do Sul. Diz-se, em tom de brincadeira, que o que não saiu no ZH não aconteceu; ou, ainda, que o ZH é nosso diário oficial. Segundo informações no site da própria Rede Brasil Sul (RBS) - empresa à qual o jornal está vinculado -, pesquisa realizada pelo Ibope informa que, em novembro de 2004, havia 1.369.000 leitores habituais do jornal no Rio Grande do Sul.

Segundo Berger (1996), esse é o jornal de referência dominante por pertencer ao grupo RBS, que possui o canal de televisão afiliado à Rede Globo e assim detém um dos componentes de dominância no cenário da comunicação no Brasil. Ainda de acordo com essa autora, o processo de institucionalização do ZH passou, também, pela anulação da concorrência, tornando-se "o jornal gaúcho", o que lhe confere um poder performativo, formal, que dá realidade ao que nomeia, que institucionaliza o que diz, que anula simbolicamente o que omite. Nesse contexto de inexistência de escolha - ou se lê ZH ou não se está informado - o leitor que garante a existência material do veículo não é aquele que se identifica com a sua linha editorial, é um leitor constrangido. $\mathrm{O}$ fato do jornal ser o mais lido no estado apenas comprova a supremacia, não a preferência, já que não há preferência em face da ausência de opção (BERGER, 1996).

Trabalhos envolvendo o ZH não são novidades no contexto acadêmico do Rio Grande do Sul. Alguns desses estudos são apresentados adiante, como um recurso para a construção do contexto dessa análise.

Berger (1996) analisa a construção simbólica de um movimento social pela grande imprensa, estudando as relações conflituosas - evidentes, invisíveis, de enfrentamento e de convivência - que marcam o encontro entre o Movimento dos Trabalhadores Rurais Sem Terra (MST) e o ZH. Adotando a referência de campos de poder, a partir de Bourdieu (1996), a autora analisa um e outro na luta específica em torno do seu capital: no campo do jornalismo, a credibilidade; no campo da política, o poder, confluindo, ambos, na luta pelo poder simbólico.

Brasil (2000) aborda como uma coluna do ZH - "Página 10", na época, sob a responsabilidade do jornalista José Barrionuevo - viu a campanha eleitoral de 1998 (na próxima seção, algumas matérias dessa mesma coluna serão objeto de análise). Tendo participado profissionalmente dessa campanha - como membro da Casa de Cinema de Porto Alegre, empresa contratada pela Frente Popular -, o autor se encontra em uma posição privilegiada para abordar as contradições e inconstâncias dos argumentos expressos na coluna sobre a influência dos programas de televisão na definição do pleito. Em suas conclusões aponta para a atuação do jornalista como organizador de uma central de recados a serviço dos interesses das grandes empresas de marketing eleitoral.

Machado (2001) analisa as manchetes da capa do caderno "Eleições 2000", veiculado pelo ZH durante o $1^{\mathrm{o}}$ turno da disputa pela prefeitura de Porto Alegre. A autora conclui que o princípio expresso no Manual de ZH - segundo o qual todos têm direitos, inclusive o de visibilidade - não foi cumprido, sendo mostrado apenas os lados do PT e do PDT. Além disso, a pauta das manchetes foi a mesma que a dos candidatos que se opunham à administração petista, sem o contraponto da situação. Segundo a autora, o ZH se mostrou um jornal sem isenção, tomando partido ou posição, colocando seu equilíbrio e sua credibilidade em jogo.

Weber (2002, p.2) aborda a disputa pela verdade e pela ocupação de espaços políticos e espaços midiáticos entre dois sujeitos capazes de intervir na sociedade e no mercado: RBS e governo estadual. Nesse episódio, a RBS transforma seu espaço jornalístico em espaço abertamente político. Deve ser destacado que, naquele momento, a empresa se envolveu em diversas arenas de conflito:

- conflito físico - durante a Marcha dos Sem, promovida pela CUT em julho de 2001, o prédio do ZH é ocupado e são espalhados adesivos por toda a cidade com a frase "RBS/ZH mentem";

- confronto jurídico - a RBS, em novembro de 2001, aciona judicialmente o Sindicato dos Jornalistas do RS e jornalistas pela publicação do texto "A voz do dono - fabricando o consenso: o caso Ford"; 
- confronto acadêmico - solicitação à editora Univali de alteração da capa (sob ameaça de ação judicial) do livro editado a partir da dissertação de mestrado "O fundo do espelho é outro - quem liga a RBS liga a Globo", defendida no Programa de Pós-graduação em Comunicação/UFRGS. O confronto com o governo girou em torno da permanência ou não da empresa Ford no estado.

\section{A construção simbólica de governar e governador}

\section{Contexto e intertextualidade}

Segundo Bresser-Pereira (1998), a eleição do presidente Fernando Henrique Cardoso consolidou um pacto político modernizante de caráter social-liberal. Esse pacto governou entre 1994 e 2000 e incorporou as visões da política da terceira via e da governança progressista. Em sua permanência no poder, respondeu às pressões internacionais pela redução do tamanho do Estado adotando a referência da nova administração pública (NAP) para implementar um processo de reforma administrativa.

A NAP (ou administração pública gerencial, como ficou conhecida no Brasil) se constituiu em um programa estratégico disseminado internacionalmente, a partir dos países anglo-saxões dos quais se origina, com o apoio de centros de ensino e pesquisa e com o reforço das agências internacionais de cooperação financeira. A partir de uma crítica de corte sistêmico-funcionalista que trivializa os problemas governamentais utilizando termos como "tamanho", "obesidade", "deficiência congênita", "funcionamento patológico" além, é claro, da exploração do estereótipo negativo da burocracia -, prescreve processos de endoprivatização, através dos quais a administração pública seria invadida e conquistada pelo espírito empresarial.

A defesa dessa prescrição se faz através da disseminação de modismos gerenciais mitificados, apresentados como caminhos garantidos para o sucesso. Sua disseminação incorpora uma estratégia de construção discursiva com dois focos. Em primeiro lugar, livros e artigos utilizam recursos de retórica para "provar" seus argumentos. A modalidade mais usada foi a de apresentar casos "bem-sucedidos" de gerentes inspirados que derrotaram o peso da burocratização. Já a etapa crítica de construção simbólica da endoprivatização envolveu a substituição da linguagem da administração pública pela do gerencialismo: coletivo/individual, cidadão/cliente, valor/interesse, emancipação/compensação, eqüidade /eficiência, carreira/ emprego, formalismo/inovação, vocação/auto-interesse etc. $\mathrm{O}$ apelo à figura do gerente e a disseminação do instrumento dos contratos de gestão são expressões dessa construção, remetendo à imagem de firmeza e eficiência no manejo bem-sucedido dos negócios.

Paula (2003) identifica, nesse mesmo período, a emergência do que denomina "administração pública popular", a partir de experiências de governos das Frentes Populares - coligações partidárias usualmente lideradas pelo PT e que conquistaram a eleição em diversas prefeituras. Segundo a autora, ali se experimentaram novos arranjos organizacionais que abriram o aparelho de Estado para a participação da população. Dentre essas práticas são destacados o orçamento participativo (OP), conselhos gestores de políticas públicas e o Fórum Social Mundial (FSM). Ainda que se possa discordar de Paula (2003) em sua visão extremamente otimista quanto à qualificação dessas práticas como alternativas ao Estado gerencial (a esse respeito ver, por exemplo, MISOCZKY, 2002a), é preciso reconhecer que se trata de construções discursivas diferenciadas. Nessas, as palavras-chave são "democracia participativa", "cidadania", "deliberação pública", "direitos sociais", "inclusão", "espaço público". Além disso, sendo Porto Alegre uma cidade símbolo, tanto do OP, quanto do FSM, nesse período, é inegável a relevância dessas experiências para este estudo. 


\section{Eleições de 1994: Antônio Britto (PM DB) x Olívio Dutra (PT) ${ }^{3}$}

Uma simples passada de olhos no conjunto das matérias selecionadas para representar a cobertura do $\mathrm{ZH}$ dessas eleições evidencia o tema-chave desse processo: as privatizações. Esse tema vai aparecer de forma expressa, mas também como crítica à burocratização, aos gastos e dívidas públicos, à pressuposta ineficiência gerencial.

Já no mês de agosto, o editorial do dia 3 dissemina, em tom imperativo, a imagem do "fracasso estatal", ao abordar o setor de telefones celulares. Em tom alarmista intitula uma reportagem de 22-8-1994, "Dívida desafio o próximo governador". Nesse texto, consta um quadro síntese - "Números que assustam". Essas nominalizações abrem o editorial do dia seguinte, "Uma pesadíssima herança", onde, através de modalidades com pretensão de verdade é declarado que:

Mais do que nunca será impositiva uma reforma administrativa de profundidade. [...] o não provimento de cargos vagos, a dispensa de servidores não amparados pelo estatuto da estabilidade, a supressão de órgãos viciados pela ineficiência ou o paralelismo de funções. [...] São elas contudo tão essenciais à saúde financeira do Rio Grande como uma opção decidida pelas privatizações.

Em novo editorial, logo em 25-8-1994 - aparentemente, dedicado às maiores preocupações dos gaúchos, a partir de pesquisa do Ibope, todas se referindo a políticas sociais, com destaque para saúde e educação -, é retomado o tom imperativo e utilizada a antítese para expressar uma pressuposição: "Urge que o Estado brasileiro seja afastado de setores em que sua ingerência não se justifica, para que possa concentrar-se naquelas que dizem respeito ao seu papel precípuo."

Em editorial de 21-9-1994, um acidente ocorrido na Via Dutra, que liga São Paulo ao Rio de Janeiro, é trazido para introduzir a mesma pressuposição:

Está na hora de o governo não mais protelar soluções que se impõem por sua obviedade. A privatização de empresas públicas que se tornaram peso morto para o Tesouro e de serviços que o Estado não consegue mais manter figura hoje entre as prioridades nacionais.

Dois dias antes da votação, Ana Amélia Lemos, diretora da RBS/Brasília e articulista há muitos anos do ZH, apresenta, em coluna assinada de 1-10-1994, uma visão do processo eleitoral que ilustra o esforço de despolitização empreendido pelo jornal no contexto dessas eleições. Vejamos a pressuposição expressa em tom de senso comum: "O eleitor, depois da decepção de 1989, recolheu-se. Substituiu a emoção e a paixão pelo pragmatismo e racionalidade. [...] O bolso é mais importante que a ideologia."

Já no $2^{\text {o }}$ turno entre Antônio Britto e Olívio Dutra, novo editorial, do dia 18-10-1994, retoma as pressuposições e, sempre em tom imperativo, apresenta sua agenda como inevitável:

O novo governador não poderá escapar, ainda, de realizar uma reforma administrativa que racionalize a utilização dos recursos humanos mantidos pelo erário. [...] modelos mais ágeis podem ser adotados daqui para a frente, que renderão dividendos consideráveis a médio prazo. A atual forma esclerótica e deficitária é que não pode permanecer.

Novamente, como já havia ocorrido no $1^{\circ}$ turno, uma pesquisa do Ibope sobre problemas mais graves na visão dos eleitores serve como desculpa para reafirmar a pressuposição da indispensável "redução da máquina administrativa. Não cabe ao Estado empregar, mas sim adotar uma política de estímulo à produção". ("Compromisso efetivo" - editorial de 30-10-1994).

\footnotetext{
${ }^{3}$ O governo que se encerrava era liderado por Alceu Collares, do PDT, após um enorme desgaste pela tentativa de reestruturar a educação - a secretária Neusa Canabarro também era esposa do governador. Olívio Dutra vinha de um mandato como prefeito de Porto Alegre (1989-92), na primeira vitória da Frente Popular no estado.
} 
Entrevistas com os dois candidatos são publicadas no dia 6-11-1994. As manchetes chamam a atenção: "Disputas atrapalham estado" e "Paz na educação é indispensável" - na entrevista de Antônio Britto; "Objetivo é reduzir cargos" e "Professores foram desrespeitados" - na de Olívio Dutra.

Britto é apresentado como um futuro governador conciliador, pacificador de conflitos. Olívio, com uma agenda compatível com a imagem da redução indispensável do Estado e, ao mesmo tempo, como portador de ressentimentos com antigos conflitos e, portanto, sujeito a retomá-los. Além disso, no texto, Britto é apresentado como quem não demitirá servidores, sequer sob a forma de demissões voluntárias (o que de fato viria a ocorrer durante seu governo), enquanto Olívio - na própria manchete, bem como no texto, é aquele que reduz o quadro de pessoal, inclusive, com referência à sua administração na prefeitura de Porto Alegre, onde reduziu os gastos com a folha de pagamento. Assim, é retomada a mesma estratégia do editorial às vésperas do $1^{\circ}$ turno - os candidatos não são tão diferentes assim com relação ao conteúdo do governo, ambos reduzirão o tamanho do Estado. Suas diferenças residem na metáfora da paz (Britto) e do conflito (Olívio).

"Dia de decisão" é o título do editorial do dia de votações. Nele, como não poderia deixar de ser, encontra-se novamente a pressuposição do imperativo da modernização do Estado, entendida como decorrência natural de um diagnóstico que, abusando de equivalências, metáforas, modalidades e nominalizações, apresenta um quadro negro: "[...] exaurido em seu gigantismo, amarrado em sua burocracia, desperdiçado em atividades que não lhe competem, imobilizado pela falta de recursos para proporcionar à sociedade que o sustenta um retorno satisfatório pelos tributos que paga." Nesse editorial se destaca uma declaração expressa que aparece pela primeira vez no discurso da cobertura das eleições produzido pelo ZH, ainda que estivesse subjacente à pressuposição da ineficiência: "Modernizar a ação do Estado, no entanto, será um imperativo para o futuro governador, até para que possa ser respeitado, ao término de seu mandato, como bom administrador."

"O critério da competência" é o título do editorial que celebra, no dia 18-11-1994, a vitória de Antônio Britto e pressupõe "expectativas altamente positivas em relação à administração a instalar-se em $1^{\circ}$ de janeiro. [...] o futuro governador também renovou compromissos com a reforma administrativa, com a abertura de serviços públicos à iniciativa privada, com o saneamento das finanças públicas [...]."

"No caminho certo", editorial de 22-11-1994, retoma em tom imperativo a relação entre eficiência e privatizações. Até aquele momento, Britto se mostra vago com relação a esse último tema. No dia anterior, na reportagem "Britto quer mais eficiência nas estatais", o coordenador do plano de governo afirma que "o foco do empenho concentrado do novo governo será a melhoria da qualidade, [...] mais eficiência, [...] um padrão de desempenho melhor." No entanto, afirma que não existe nenhuma intenção do novo governo de privatizar qualquer estatal. Deve ser observado o tom de censura e a utilização da modalidade "obrigação", presente no editorial em que ZH reage a essas declarações: "[...] os problemas do Estado são tão complexos que não bastam as boas intenções. Se pretende tornar a máquina pública realmente eficiente, o novo governo não pode descartar de pleno a privatização de estruturas reconhecidamente ineficazes."

No dia 26-12-1994 se inicia uma série de editoriais que irão até o dia seguinte à posse, sempre em torno do mesmo tema. "A hora das privatizações" (editorial de 26-12-1994):

O papel do Estado não é administrar siderúrgicas, como também certamente não é enfeixar monopólios anacrônicos e intocáveis, a exemplo do petróleo e das telecomunicações. Em verdade, o seu papel é o de promover o bem comum, o que só alcançará deixando de imiscuir-se em áreas que não lhe são próprias e nas quais se vem revelando um gerente perdulário e ineficiente.

\section{"A única alternativa" (editorial de 27-12-1994):}

É positivo que o futuro governador se preocupe com a arrumação da casa - a começar pelo redimensionamento do quadro de pessoal do próprio Palácio Piratini. Com um exemplo convincente de austeridade, o governo certamente encontrará apoio e parceria da sociedade na promoção do desenvolvimento do Estado. 
"A moratória da imprevisão" (editorial de 29-12-1994): "Para enfrentar essa dura realidade, a alternativa é partir para uma espécie de economia de guerra, reduzindo cargos de confiança e eliminando órgãos supérfluos e de menor importância." O RS de Antônio Britto" (editorial de 31-12-1994): "Antônio Britto assume um Estado produtivo com uma máquina pública falida." "Governar o governo" (editorial de 2-11995): [referindo-se ao discurso de posse do novo governador] Eis por que situou, como o mais grave problema a resolver, o próprio governo do estado. Deriva daí a imperativa necessidade de governar o governo, de repensá-lo, indo muito além da forma cosmética de uma mera reforma administrativa.'

Iniciado o governo, o $Z H$ mantém seu tom prescritivo, sempre partindo de pressuposições, sempre em tom imperativo, algumas vezes, recorrendo a metáforas, muitas vezes, a equivalências que reduzem diferenças e apresentam substituições, como se fossem sinônimos. Editorial de 4-1-1995, "O ciclo da austeridade":

O governador Antônio Britto mostrou [...] vai mesmo atacar o centro nervoso do problema de caixa do estado, que são os ônus da manutenção de uma máquina obviamente hiperdimensionada e notoriamente perdulária. Determinou [...] o corte de $25 \%$ de todos os gastos de custeio da administração direta e indireta [...]. Proibiu os investimentos [...]. Suspendeu todas as licitações e celebração de contratos para obras e sustou, até que haja disponibilidade, o pagamento de fornecedores.[...] ordenou a redução de $25 \%$ dos cargos em comissão e funções gratificadas. [...] De qualquer modo, eis aí um excelente ponto de partida [...]. A estrutura burocrática não pode ser fim em si mesma, mas instrumento de promoção do bem comum. [...] recolocar o Estado no papel que lhe é precípuo, diminuindo-lhe as dimensões e conferindo-lhe eficiência.

Em 5-1-1995 o governador anuncia o "fim do Estado-empresa", incluindo projetos de extinção, fusão, incorporação ou transferência de funções envolvendo oito estatais. O editorial do dia seguinte celebra "A extinção dos dinossauros". A metáfora é retomada em nota na coluna "Página 10", assinada pelo jornalista José Barrionuevo, no dia 11-1-1995, tratando da tramitação dos projetos na Assembléia Legislativa; dessa vez, com o acréscimo de imagens para reforçar a metáfora.

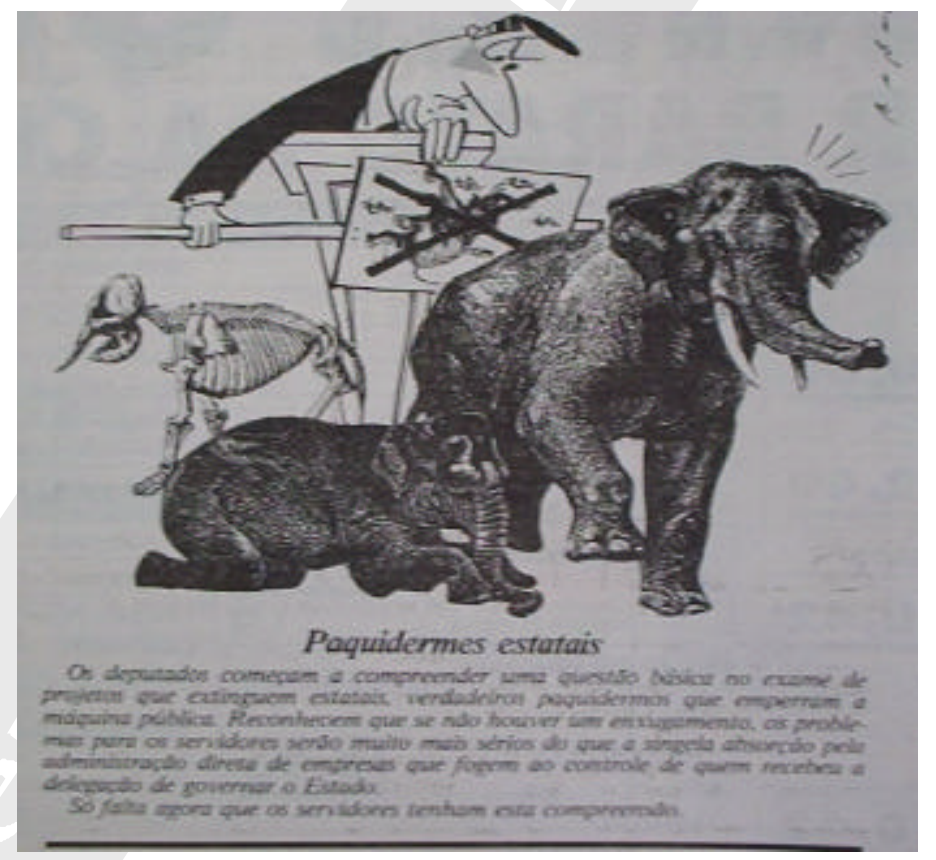

Encerrado o processo de aprovação e implementação desses projetos, editorial do $Z H$ comemora outro feito do governo (em 19-2-1995) - "Qualidade no serviço público", celebrando a adesão ao Programa de Qualidade Total (PQT) coordenado pelo empresário Jorge Gerdau Johannpeter:

A busca da qualidade pressupõe uma renovação de procedimentos, uma administração realmente profissional e a adesão, mediante treinamento e estímulos, de todos que participam da produção de 
equipamentos ou serviços. Qualidade é indispensável para os tempos de crescente competitividade e, para muitas empresas, dela depende a própria sobrevivência. No Brasil, onde alguns serviços são monopólio do Estado, neles, programas de qualidade ficaram à deriva ou foram relegados à última das prioridades: para que qualificar o que só uma instituição fornece? Abrir o campo à concorrência será fundamental para o êxito da iniciativa.

Observe-se a utilização da modalidade "com pretensão de verdade", a insinuação de que essa resposta é única e decorrência natural de uma questão apresentada como se fosse de indiscutível relevância.

Ao registrar os primeiros meses de governo, reportagens enfatizam a imagem construída com a ajuda do próprio $Z H$ no decorrer da campanha - Antônio Brito como um homem de paz: "Busca de diálogo marca o início do governo Britto" (9-4-1995); "Não é preciso dar pontapé em porta aberta" (entrevista com o governador em 10-4-1995) e "Diálogo é a palavra preferida no Piratini" (16-4-1995).

\section{Síntese provisória}

\section{Contexto}

Início da disseminação do discurso da nova administração pública (NAP), veiculado durante a campanha para presidência pela candidatura Fernando Henrique Cardoso.

\section{Interdiscursividade}

Referência às palavras-chave do discurso da NAP, com destaque para os termos que induzem à inevitabilidade da redução do tamanho do Estado e das privatizações.

\section{Definições}

Governar é privatizar. O governador é um administrador conciliador.

\section{Símbolos}

O símbolo positivo é a empresa eficiente; o negativo é o governo ineficiente.

\section{Eleições de 1998: Olívio Dutra (PT) x Antônio Britto (PMDB) ${ }^{4}$}

No início dessa campanha eleitoral o $\mathrm{ZH}$ retoma seu discurso sobre a imparcialidade, afirmando em editorial do dia 2-8-1998 que a função da imprensa é facilitar o esclarecimento popular sem comprometer-se com facções políticas. Porém, nota publicada pelo PT, em 6-8-1998, contesta uma série de afirmações feitas na coluna "Página 10", afirmando que essas expressam "o compromisso com a candidatura oficial do senhor Antônio Britto." Está dado o tom de conflito, entre o ZH e o PT, que será mantido durante essa campanha, o próximo governo e a campanha de 2002.

A revisão das matérias publicadas durante esse período pré-eleitoral dá a impressão que, de modo muito diferente das eleições de 1994, disputadas por esses mesmos candidatos, não existe, de fato, uma disputa. Não existe mudança no discurso do $Z H$, apenas parece que a ênfase anterior não se faz mais necessária. Afinal, as definições construídas pelo jornal vinham sendo efetivadas pelo governo Antônio Britto. Exemplo dessa afinidade se encontra no editorial de 24-9-1998, "Qualidade na área pública":

É animadora a constatação de que, depois de envolver milhares de empresas e a área governamental no Rio Grande do Sul, o Programa Gaúcho de Qualidade e Produtividade constitui parâmetro nacional. [...] a própria Ministra da Administração, Cláudia Costin, fez questão de

\footnotetext{
${ }^{4}$ Ao final do governo Britto havia sido implementado um programa de demissões voluntárias, diversas estatais foram privatizadas e setores do funcionalismo (como os professores) se encontravam com salários extremamente defasados. Por outro lado, o programa de incentivos fiscais investiu na atração de grandes empresas (como a GM e a Ford), estabelecendo um cenário de disputas políticas que se prolongaria até o governo seguinte.
} 
ressaltar o fato de que o programa em implantação no âmbito federal foi inspirado na experiência gaúcha.

Efetivada a vitória de Olívio Dutra, tudo muda nas páginas do $Z H$ ! O editorial de 26-10-1998, “A opção pela alternância", retoma o tema da conciliação e apresenta sua agenda para o próximo governo: "Entre os desafios que aguardam o futuro mandatário está o de, sem abrir mão do programa com o qual conquistou o eleitorado, manter o que vem mostrando resultados concretos em gestões anteriores e na atual."

A imagem do governador como um administrador é desafiada pela linguagem e pela imagem de Olívio. É interessante como $Z H$ destaca os termos gauchescos em "A nova linguagem do poder", onde se encontra, inclusive, um glossário com as palavras e expressões mais utilizadas pelo governador. O glossário pressupõe que essa linguagem é desconhecida dos próprios gaúchos; portanto, indica que o eleito é estranho ao meio que o elegeu, é pouco moderno, pouco urbano, pouco erudito. Deve ser destacado que a imagem de Olívio como pouco moderno, atrasado, será retomada com ênfase durante a crise em torno dos subsídios às montadoras de automóveis, como se verá mais adiante.

Em editorial de 6-11-1998, começa a ser explicitada a preocupação com as escolhas do novo governo:

[...] garantiu que a ênfase de seu governo será a pequena e média empresa, particularmente a ligada à agroindústria. São metas coerentes, mas não podem implicar o risco de conflito com a União, nem de discriminação do grande capital. [...] O futuro governador dos gaúchos reiterou que vai manter os acordos firmados pelo atual governo com o setor privado envolvendo incentivos oficiais [...] Insistiu, porém, que a partir de sua posse, a prioridade passa a ser a empresa de pequeno e médio portes. [...] Obviamente, convém que não exclua futuros grandes projetos, pela capacidade que têm de agregar tecnologia e crescimento ao seu redor.

E insiste, em editorial do dia seguinte, que "não se pode descartar nenhuma oportunidade em nome de teses ou de preconceitos."

O governador eleito, ainda antes de sua posse, expressa sua oposição aos incentivos fiscais, na publicação de entrevista com Olívio, no dia 7-11-1998, intitulada "A guerra fiscal é uma loucura", o texto de introdução apresenta-o como um criador de conflitos: "Antes mesmo de tomar posse, Olívio Dutra já comprou uma briga com o empresário Jorge Gerdau Johannpeter." Essa imagem continua com os títulos de matérias sobre a transição: "Transição confirma confronto" (13-11-1998); "Transição conturbada" e "Próximos lances do confronto" (15-11-1998) e "Nervos à flor da pele" (4-12-1998).

Ainda que a decisão de não transmitir o cargo tenha sido de Britto, fica implícito que isso ocorre pela impossibilidade de enfrentar o clima de confronto gerado pelo eleito:

A Praça da Matriz estará tomada de bandeiras vermelhas. Na Duque de Caxias, será armado o palco onde Olívio discursará depois da posse para milhares de militantes em festa. Antônio Britto não estará esperando Olívio no Palácio Piratini, porque não há clima para abraços, discursos, flores, afagos. (coluna assinada por Rosane de Oliveira, editora de política, em 24-12-1998)

Em meados de novembro, a Assembléia Legislativa aprova o projeto de lei que institui incentivos para 12 grupos produtivos privados. O ZH comemora (18-11-1998): "Em todo o mundo, inclusive no Brasil, benefícios fiscais e creditícios constituem um mecanismo fundamental para a manutenção e atração de investimentos." Novamente em 26-11-1998: "A parceria entre os setores público e privado é uma tradição no Rio Grande do Sul e precisa ser preservada." Em 29-12-1998, um último esforço de pressão, em matéria intitulada "Rumo às privatizações", $Z H$ afirma que

segmentos mais moderados do futuro governo não acreditam que Olívio Dutra vá conseguir manter seu discurso contrário às privatizações. Estão convencidos de que [...] avançará no processo de reforma do Estado implementado por Antônio Britto. 
Isso não acontece! O novo governo nega novas privatizações, questiona os incentivos fiscais e começa a implementar um processo de orçamento participativo. Em 22-2-1999 a editora Rosane de Oliveira afirma que, mesmo em face da crise financeira, a privatização passa longe do projeto da Frente Popular. Ainda que reconhecendo tal opção como legítima, alerta para o engessamento e os efeitos políticos adversos:

Como explicar para uma comunidade que sonha com asfalto que o barro vai continuar fazendo parte de sua vida por muito tempo? Quando o orçamento participativo estadual já estiver implantado, os cidadãos serão chamados a avalizar o sacrifício.

A crise entre o governo do Estado e as montadoras (GM e Ford) é deflagrada formalmente em 13-3-1999, quando começa a se desenvolver um processo de negociação de pontos dos contratos assinados. Esse processo é qualificado por editoriais do ZH como "Teia de conflito' (4-4-1999); e é retomada a necessidade de conciliação no editorial "O Rio Grande partido ao meio" (11-4-1999). O governador é apresentado, sistematicamente, como a imagem do atraso e do retrocesso (charges publicadas nos dias 23 e 24-3-1999).
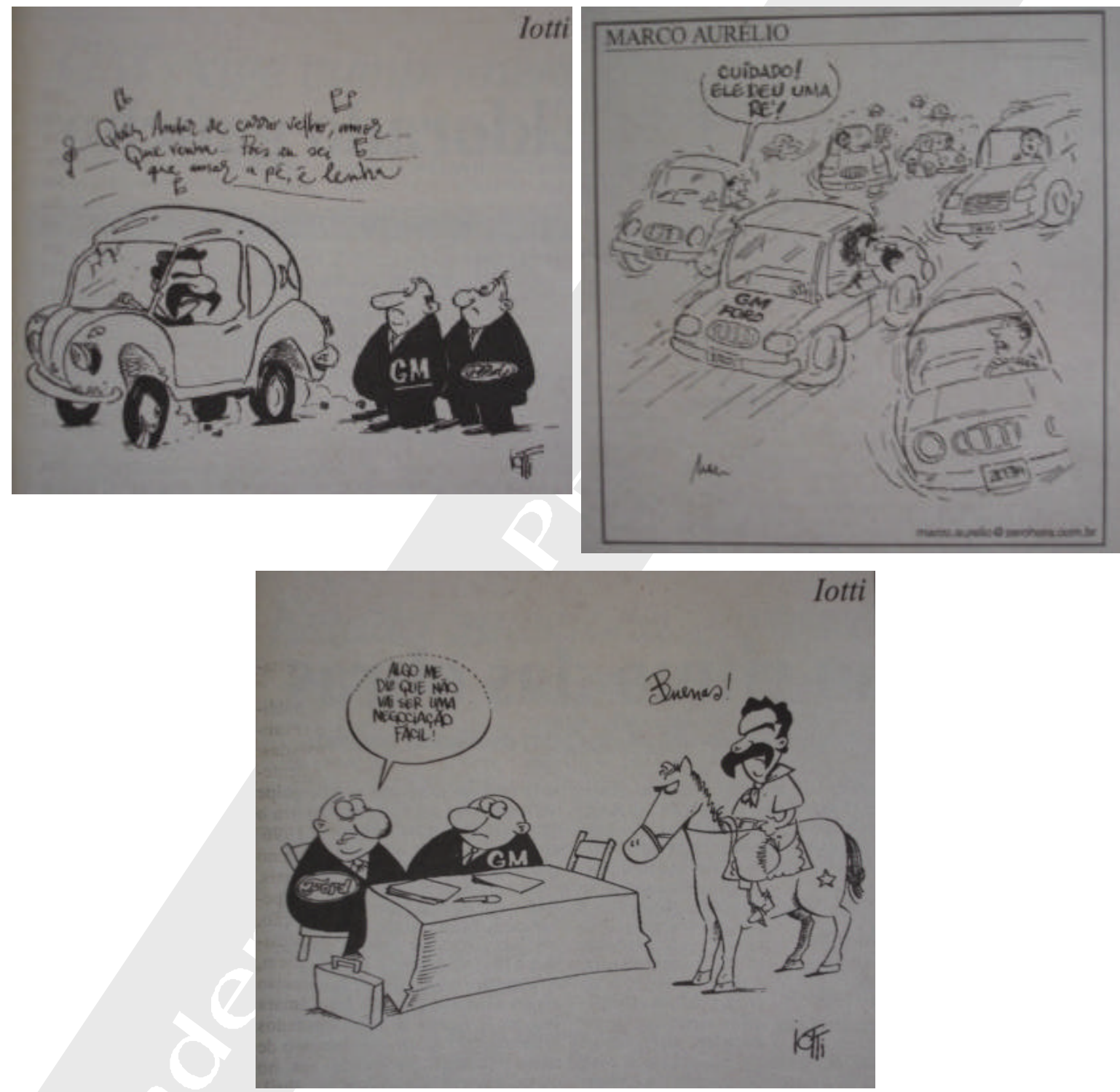
O editorial "Desfecho melancólico" (29-4-1999), que trata da decisão da Ford de instalar-se na Bahia, pressupõe que os interesses da empresa são os interesses de toda a sociedade gaúcha: "A sociedade riograndense, que lutou muito e fez grandes sacrifícios para conquistar as montadoras de automóveis, merece compensações à altura das expectativas frustradas." Insistindo, no dia seguinte, com pressuposições nunca evidenciadas com dados: "O maior prejuízo que o Rio Grande irá sofrer com a desistência da Ford [...] nunca chegará a ser avaliado inteiramente, tal o seu vulto."

\section{Síntese provisória}

\section{Contexto}

O discurso da NAP está sedimentado, com a aprovação de diversos dispositivos legais que reformam o aparelho de Estado e com a realização de diversas privatizações. A guerra fiscal está em pleno vigor entre os estados, chegando a ponto de ameaçar o pacto federativo.

\section{Interdiscursividade}

Referência às palavras sedimentadas da eficiência e do Estado não mais como provedor de serviços, mas como agente facilitador das relações no mercado.

\section{Definições}

Governar é facilitar as relações no mercado. O governador é o administrador conciliador, incentivador do mercado.

\section{Símbolos}

O símbolo positivo é a empresa moderna, com tecnologia incorporada; o negativo é o suposto atraso da tradição e de setores produtivos a ela ligados - agricultura e empresas de médio e pequeno porte com menor incorporação de tecnologia.

\section{Eleições de 2002: Germano Rigotto (PM DB) x Tarso Genro (PT) ${ }^{5}$}

O ZH marca o início de mais esse processo eleitoral com o tema que nunca tirou da pauta, ao longo de todo o governo Olívio: "Guerra fiscal retorna ao palanque" é o título de reportagem de 17-8-2002. Destaque-se que disputava o $1^{\circ}$ turno, agora pelo PPS, o ex-governador Antônio Britto. Em coluna assinada pela editora de política, em 8-9-2002, pode-se encontrar uma síntese da construção que o jornal faz durante essa fase das eleições:

A mensagem que permeia os comerciais de Tarso é "não vote em quem privatizou o Estado". A propaganda compara o crescimento de 0,8\% no governo anterior com os $11 \%$ do atual para sustentar que a saída da Ford não comprometeu o desenvolvimento do Estado. Ainda que os dois digam que querem falar do futuro, o passado é o cerne da propaganda. Se disputarem o $2^{\circ}$ turno, como indicam as pesquisas, Britto e Tarso terão que dedicar mais tempo aos programas de governo.

Ou seja, a revisão do passado é desqualificada, já que nela aparecem dados que contradizem as pressuposições e as metáforas sobre o atraso a que o abandono das privatizações e da guerra fiscal levaria $o$ Rio Grande do Sul. Como nada disso aconteceu, tratar do tema é irrelevante!

Em 21-9-2002, o ZH começa a considerar a possibilidade de que o $2^{-}$turno exclua Britto da disputa. Dados de pesquisas mostram surpreendente e rapidíssima redução da diferença entre Rigotto e Britto - de 27 para 8

\footnotetext{
${ }^{5} \mathrm{O}$ governo Olívio termina extremamente desgastado. Entre outros fatores certamente a guerra aberta travada contra ele pelo próprio $Z H$, que manteve durante todo o período de governo a disseminação da imagem de um governador gerador de conflitos em todas as frentes possíveis. Além disso, a polêmica envolvendo a Ford se estendeu durante os quatro anos.
} 
pontos em apenas 25 dias. Quem acompanha as sondagens de intenção de voto publicadas pelo $Z H$ nas últimas décadas não se surpreende com rápidas viradas.

Durante o $2^{\underline{0}}$ turno, o ZH encontra nas marcas e conteúdo da campanha de Rigotto o mote para a construção de seus argumentos: "Parece ter ficado para trás um estágio de campanha fortemente marcado por ataques entre os disputantes. [...] O que requerem os cidadãos deste Estado são respostas realistas, inequívocas e racionais."

Para compreender o tom morno adotado pelo $Z H$ durante essa eleição é preciso lembrar que no cenário nacional tudo indicava, desde o $1^{\circ}$ turno, a inevitável vitória de Lula. No Rio Grande do Sul, o $Z H$ precisa moderar suas construções discursivas para seguir a linha de aparente neutralidade, quase adesão, ao candidato do PT à presidência, seguindo a postura da Rede Globo. Assim, sua intervenção no processo estadual se volta para as pesquisas eleitorais. Os resultados das pesquisas contratadas pela RBS foram tão discrepantes de outros levantamentos quanto do resultado final. Em 3-11-2002, o próprio presidente da RBS assina um editorial, em que pede desculpas ao Centro de Pesquisa Correio do Povo, que chegou a resultados precisos em seu levantamento de intenção de voto e havia sido tratado com menosprezo durante todo o tempo pelos comunicadores da RBS. Além disso, convida representantes da sociedade para constituir uma comissão independente para "reavaliarmos o nosso procedimento na contratação e divulgação de pesquisas eleitorais." Podemos observar que a frase induz a que se considere que o problema se encontra em procedimentos de escolha dos organismos de pesquisa, e não na própria RBS.

"O jeito Rigotto de governar" começa a ser enaltecido: "Germano Rigotto tem todas as condições políticas para realizar um governo diferente do perfil autoritário de Olívio, por ser ele um conciliador (coluna "Página 10" em 29-10-2002). "Rigotto aposta em diálogo contra pressão social" (manchete de reportagem em 1-122002); "Rigotto, a opção pelo coração" (usando metáfora, a partir da marca de campanha, em editorial de 3112-2002, véspera da posse): "[após mencionar alguns desafios] e que ele mais facilmente superará, se preservar o espírito de reconciliação que o conduziu ao poder." O tom declarativo continua após a posse: "A ordem é desarmar os espíritos" (2-1-2003), "A paz gaúcha" (1-2-2003); "Rigotto prega austeridade e cultiva boas relações" (2-2-2003); "Cem dias de diálogo e austeridade" e "Cem dias sem conflito" (10-4-2003).

Parte da construção discursiva de louvar um símbolo envolve o repúdio à sua antítese. Portanto, Olívio não foi esquecido, continua sendo apresentado como um criador de conflitos:

O relatório do governo não se refere ao clima de destrutivo antagonismo que se criou no estado nesses quatro anos, fato que marcou decisivamente as relações econômicas, políticas e sociais e que determinou o resultado eleitoral com a inequívoca derrota do modelo adotado. (editorial de 27-122002)

"Olívio, visão social e conflito": "A forte identificação ajudou a conter insatisfações, mas também a aprofundar atritos entre empresários e produtores rurais, e mesmo entre corporações aliadas de primeira hora, como as de servidores." (editorial de 30-12-2002)

Reportagem (1-12-2002) sobre sua indicação para ministro das Cidades retoma o outro símbolo vinculado à Olívio, a do atrasado apego à tradição. Texto introdutório: "Ficou morno o chimarrão do governador Olívio Dutra, pelo menos, o da primeira cuia antes do almoço de quinta-feira." A foto sob a manchete "A Ford foi para a Bahia, mas não ficamos órfãos" é de Olívio sorvendo um amargo. Há ainda uma caixa de texto com o título "O ramo de arruda" e uma foto em que uma senhora oferece um ramo de arruda a Olívio.

Nesse novo cenário, o $Z H$ retoma suas prescrições sobre o que deve ser governar: "Temos inteligência, conhecimento, massa crítica, determinação e experiência para racionalizar e modernizar as estruturas públicas" (editorial de 1-12-2002). Reportagens (2-11-2002 e 8-12-2002; bem como a charge mostrada adiante, publicada no dia 16-2-2003) celebram o final de uma das mais conhecidas marcas do que Paula (2003) chamou de "administração pública popular" - "Marcas da gestão Olívio Dutra serão esvaziadas: orçamento participativo e gabinete da reforma agrária serão modificados por Rigotto" e "Orçamento participativo tem dias contados". 


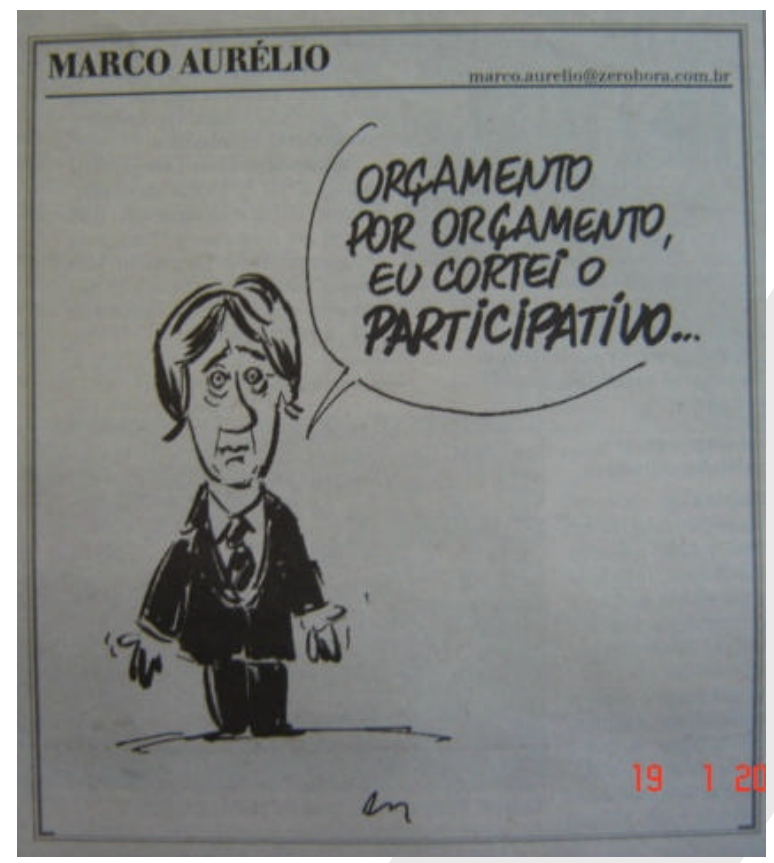

Ao mesmo tempo, ZH volta à carga com as pressuposições e prescrições que disseminam uma concepção gerencialista de governar. "Governabilidade depende de novo modelo de gestão pública" - título da coluna "Página 10" em 9-3-2003, com os seguintes subtítulos: "excesso de órgãos públicos; burocracia; falta eficiência." "Rigotto prepara plano para modernizar gestão pública" e "Foco no resultado" (16-3-2003). O retorno à prática de incentivos fiscais é louvada em editorial de 44-2003 - "Vale a pena ver de novo": "Rigotto vem dizendo que para atrair investimentos está disposto a entrar na guerra fiscal. O governador também sabe o quanto seu antecessor se desgastou quando perdeu a Ford para a Bahia." Ou seja, voltamos a ser modernos e competitivos!

\section{Síntese provisória}

\section{Contexto}

O discurso da NAP ainda que sedimentado, é retomado após um período de gestão marcado pelo discurso e por algumas práticas da "administração pública popular". A eleição de Lula no cenário nacional torna o discurso relacionado a essas práticas mais palatável.

\section{Interdiscursividade}

Retomada a referência às palavras sedimentadas da eficiência e do Estado como agente facilitador das relações no mercado.

\section{Definições}

Governar é conciliar, é pacificar conflitos entre os diferentes interesses presentes na sociedade. O governador é o conciliador e modernizador.

\section{Símbolos}

O símbolo positivo continua sendo a empresa moderna, com tecnologia incorporada. O negativo é o suposto atraso da tradição e de setores produtivos a ela ligados e uma sociedade na qual os conflitos sociais sejam expressos e visíveis. 


\section{Considerações finais}

Se retomarmos as sínteses provisórias, ao final de cada episódio eleitoral, perceberemos um contínuo na linha editorial do jornal, independente dos contextos e da intertextualidade. Para o Zero Hora, governar é conciliar, e o governador deve ser um administrador modernizador.

Para aqueles que, como nós e milhares de gaúchos, lêem diariamente o Zero Hora, a sensação é que se trata de um jornal conservador - sensação mesmo, assim... sem precisão conceitual. A realização deste estudo nos permitiu, a partir dos referenciais e dos procedimentos metodológicos adotados, precisar como esse conservadorismo se expressa. Se tomarmos a palavra conservação no seu sentido de manutenção do que está, do que é, certamente nada mais conservador do que a conciliação. Sem a explicitação da existência de diferentes interesses, muitas vezes contraditórios e inconciliáveis entre si, o que domina, se reproduz; o que está, permanece. Nesse sentido, para o Zero Hora, a administração pública é o espaço de preservação do que está e do que é.

Outra constatação é a participação ativa na intertextualidade que afirma que tudo que é moderno é bom, tudo que não é moderno é atrasado. Assim, o conservadorismo é mediado por um discurso aparentemente progressista. Ou melhor, por um discurso progressista no sentido comtiano de progresso. Queríamos evitar, mas parece que as palavras de ordem do positivismo ecoam e se impõem: ordem e progresso! Eis a síntese $\ldots$

P.S. Este texto foi escrito em abril de 2005. Agora, em agosto, quando estávamos revisando para enviar a esta revista, fomos agraciadas com uma confirmação do que, em abril, parecia um encerramento singelo do artigo. A RBS-TV, braço televisivo do grupo que publica o Zero Hora, acaba de lançar uma série produzida localmente. Segundo sinopse no site da RBS, trata-se da recuperação de imagens históricas do cotidiano de Porto Alegre dos anos 1950 e 1960, que "vão integrar a nova série da RBS TV intitulada 'Ordem e Progresso"”. 


\section{Referências}

BERGER, C. Campos de confronto: jornalismo e movimentos sociais - as relações entre o Movimento Sem Terra e a Zero Hora. 1996. Tese (Doutorado) - Escola de Comunicação da USP, São Paulo, 1996. $\overline{2} \overline{0} \overline{2}$. A reestruturação da política em tempos midiáticos. Disponível em: <http://www.ilea.ufrgs.br/intexto>. Acesso em: 2 ago.

BOURDIEU, P. Sur le pouvoir simbolique. Annalles, n.3, p.405-411, 1977.

. The state nobility: elite schools in the field of power. Stanford: Stanford University Press, 1996.

BRASIL, G. A. Como a Página 10 viu a campanha eleitoral de 1998. In: GUARESCHI, P. A. et al. Os construtores da informação: meios de comunicação, ideologia e ética. Petrópolis: Vozes, 2000. p.233-242

BRESSER-PEREIRA, Luiz Carlos. Um novo Estado para a América Latina. Novos Estudos Cebrap, n.50, p.91-98, 1998.

DUSSEL, E. Ética da libertação. Petrópolis: Vozes, 2002.

FAIRCLOUGH, N. New labour, new language. London: Sage, 2000. jul. $20 \overline{0} 2$.

Representations of change in neo-liberal discourse. Disponível em: <www.cddc.vt.ed/host/Inc/Incarchive.htm>. Acesso em: 12 p.258-284.

WODAK, R. Critical discourse analysis. In: VAN DIJK, T. A. (Ed.). Discourse as structure and process. London: Sage, 1998. v.II,

GUERREIRO RAMOS, A. A nova ciência das organizações: uma reconceituação da riqueza das nações. 2. ed. Rio de Janeiro: Editora FGV, 1989.

HARDY, C.; PHILLIPS, N. No joking matter: discoursive struggle in the Canadian refugee system. Organization Studies, v.20, n.1, p.1-24, 1999.

IBÁÑEZ, T. La construcción del conocimiento desde una perspectiva socio-construccionista. In: MONTERO, M. (Coord.). Conocimiento, realidad y ideologia. Caracas: Avepso, 1994. p.37-48.

JOVCHELOVITCH, S. Representações sociais e esfera pública: a construção simbólica dos espaços públicos no Brasil. Petrópolis: Vozes, 2000.

LINCOLN, Y. S.; GUBA, E. G. Paradigmatic controversies, contradictions, and emerging confluences. In: DENZIN, N.; LINCOLN, Y. S. (Eds.). Handbook of qualitative research. $2^{\text {nd }}$ ed. London: Sage, 2000. p.163-188

MACHADO, M. B. C. Diálogo complexo: Zero Hora e as eleições. Revista de Estudos Feevale, v.24, n.2, p.127-142, 2001.

MISOCZKY, M. C. Mudanças na administração municipal: possibilidades de uma formação político-organizacional. Revista de Administração Contemporânea, v.6, n.2, p.99-122, 2002a. $\overline{2} \overline{0} \overline{0} \bar{b}$.

. 0 campo da atenção à saúde após a Constituição de 1988: uma narrativa de sua produção social. Porto Alegre: Dacasa Ed.,

PAULA, A. P. Entre a administração e a política: os desafios da gestão pública democrática. 2003.. Tese (Doutorado em Ciências Sociais) - Unicamp, Campinas, 2003.

RICOUER, P. Do texto à ação: ensaios de hermenêutica II. Lisboa: RÉS- Editora, 1989.

WEBER, M. H. Hibridação de verdades políticas e midiáticas. Disponível em: <http://ilea.ufrgs.br/intexto/v6n6/a- v6n6a4.html>. Acesso em:2 ago. 2002. 